\title{
Hamstring Strain in Soccer Players: Things the Trainer Must Know
}

\author{
Atzmon Tsur* \\ Rehabilitation Department, Galilee Medical Center, Nahariya, Israel
}

Received: November 23, 2014; Accepted: April 09, 2015; Published: May 06, 2015

*Corresponding author: Atzmon Tsur,Faculty of Medicine, Bar-Ilan University, Tzfat, Israel, Tel: 972-50-7887671; Fax: 972-49-107253; E-mail: atzmon.tsur@naharia.health.gov.il

\begin{abstract}
Acute hamstring strain injuries are common in sports that involve sprinting, kicking, jumping or high-speed skilled movements. It is generally believed that they occur during terminal swing phase of the gait cycle. Most hamstring injuries occur along the proximal musculo-tendon junction, where the muscle fibrils intersect with the tendon. A number of potential risk factors have been proposed for hamstring strain, among them fatigue, lack of flexibility, imbalance of muscular strength with a low hamstring to quadriceps ratio, and insufficient warm-up. An emphasis on neuro-muscular control and eccentric strengthening is suggested for the successful return of the soccer player to sport.
\end{abstract}

Keywords: Hamstring; Soccer Injury; Strain; Eccentric Contraction

\section{Introduction}

Of all the muscle strains associated with competitive sport, hamstring strains are the most common and problematic [1,2]. A national football league team published injury data, including data from preseason training camp from 1998 to 2007, and found that hamstring strains were the second most common injury after knee sprains [3]. Injury to the hamstring muscles is common mainly among sprinters and jumpers, but also among soccer players [4]. It may also be said that the same injury may occur in many sports fields in which acceleration, kicks or movements are performed at high speed [5-8]. The causes of hamstring strain are variables involving muscle strength imbalance, inadequate warm up, lack of flexibility, muscle fatigue, and previous strain [9]. Non-contact hamstring injuries are common in sports that include sprinting, acceleration and kicking, and have a high rate of recurrence and decreased performance levels [7,10]. The injury may be caused infrequently, as a result of contact injury, whereas in most cases, it is caused from non-contact injury, that is, due to forceful stretching [4]. It has been reported that there are more hamstring injuries at the end of each half-time of European football game, which may suggest that fatigue acts as a risk factor for these injuries $[7,11]$. The soccer player will feel sudden pain in the posterior compartment of the thigh that may only annoy him, or it may prevent him from continuing with physical activity $[12,13]$. Frustration with hamstring strain is explained by the high prevalence of these injuries and by the prolonged duration of symptoms, poor healing responses and a high risk of re-injury rate [7,14]. Also Engebretsen et al. [15] found that previous injury was a risk factor for hamstring injury after reporting 76 injuries in 508 amateur football players. Ekstrand et al. [16] reported injury rates over seven consecutive seasons from 23 professional European Football clubs and found unchanged training and competition hamstring injury rates during this period. These findings may suggest that prevention and rehabilitation programs have not been effective. The purpose of this article is to highlight the main points that the professional soccer trainer must know about hamstring strain, treatment, rehabilitation, and the risk of re-injury.

\section{Anatomy and Kinematics}

The hamstring muscle group originates at the ischial tuberosity except for the short head of the biceps which originates at the femoral shaft. The biceps femoris muscle inserts at the head of the fibula while the semitendinosus and semimembranosus muscles insert at the posterior medial side of the tibia [17]. The dynamic action of the biceps femoris is expressed by extension of the thigh [by the long head only] and flexion and lateral rotation of the knee, while the semitendinosus is responsible for extension of the thigh and medial rotation of the knee and the semimembranosus is responsible for flexion and medial rotation of the knee. All three muscles are responsible in principle for knee stability during medial trunk flexion [13]. During activity they are used for extension of the thigh and also for flexion of the knee and this due to their being involved in two joints both at once. When the hip joint is in flexion and the knee joint is in full extension, as while sprinting or kicking a ball, the group of muscles reaches maximal extension, which in certain cases may cause minute damage. This damage may be cumulative and worsen due to frequent activity at high intensity [18].

\section{Injury Mechanism}

Two factors may be involved in causing hamstring muscle injuries: one is their eccentric contraction and the other is the stretching of those muscles beyond the limits they are able to withstand. In these cases, minute damages may be caused and 
cumulate due to continuous activity in soccer. The action of the hamstring muscles at the hip joint level depends in effect, on the position of the thigh. The more the hip is flexed, the more those muscles lengthen and tension between them increases. When the thigh is in flexion over 90 degrees, it is very difficult to straighten the knee. The majority of studies indicate that in soccer that same injury occurs during the second half of the swing phase of the step when the hamstring muscles eccentrically contract in order to decelerate extension of the knee in preparation for contact of the sole of the foot with the ground. At the same time, the hamstrings contract concentrically in order to extend the hip joint [17]. It seems that the muscles become more vulnerable during the speedy transition from eccentric to concentric contraction [4]. The biceps femoris is the muscle in which more significant stretching occurs during the same phase of high-speed running making it more vulnerable than the other two muscles which compose the hamstring $[12,19,20]$. In addition, we know that during contact between the sole of the foot and the ground, the hamstring muscles contract concentrically in order to allow extension of the thigh and during that same phase of running they produce the most force [13].

In soccer for example, where sprinting is performed during rapid extension of the knee when the thigh is in flexion, the eccentric contraction of the hamstring is supposed to prevent hyperextension of the knee joint, but exactly at this phase, the same group of muscles reach maximal stretching and may therefore be injured.

In most cases the damage occurs in the musculo-tendinous junction where the nearby muscle tissue found close to the junction is damaged [6]. The most vulnerable muscle of the three is the biceps femoris, and after that, the semitendinosus and only rarely, is the semimembranosus involved.

Noted among the risk factors which may influence damage to be caused to the hamstring muscles is the existence of weakness in those muscles, fatigue, lack of flexibility and lack of balance between the force of the hamstring in eccentric contraction and of the quadriceps in concentric contraction. In addition, limited flexibility of the quadriceps as well as muscle force and defective coordination between pelvic and trunk muscles, may contribute to the hamstring's vulnerability [12].

\section{Degree of damage caused}

Damage to the posterior muscles of the thigh may be divided into three degrees according to the severity of injury and pain criteria, weakness, and loss of range of motion as follows $[4,12,13]$.

First degree tear, involves a small amount of muscle fibers and causes mild local swelling and insignificant limitation of muscle strength and movements of the involved limb. Return to physical activity will be possible within 15 days from the time of injury.

Second degree tear, causes more damage to the muscle, hematoma, difficulty in muscle contraction and limitation to movement of the involved limb. In ultrasound imaging, the same hematoma may be seen in or between the muscles. Return to sports activity will be possible within a period of 30-45 days.

Third degree tear, involves the width of the muscle and causes complete loss of ability to contract as a single unit. It occurs mainly as a result of soft tissue avulsion alone or with a bone fragment detached from the ischial tuberosity, at the proximal tip of the muscle, but is considered to be very rare [20]. When this type of injury occurs to a soccer player he may often need surgical intervention [4,21-23]. Magnetic resonance imaging or sonography will aid in the diagnosis of the scope of damage caused. Suspension of sports activity should last between 45 days to 3 months.

\section{Clinical Symptoms}

Injury to hamstring muscles at the time of occurrence is expressed in the form of sharp pain in the same region. In mild cases, the soccer plays regards the pain only as annoyance, whereas in more severe cases, he is unable to continue in the competition. The hamstring muscles are rich in fast-twitch contractile fibers and so they are very sensitive to the appearance of Delayed Onset Muscle Soreness (DOMS) which appears after exertion that the body is not accustomed to. This may at times mislead the treating physician when he is arriving at a diagnosis.

\section{Diagnostic Imaging Methods}

Ultrasound examination as well as Magnetic Resonance Imaging (MRI) is recommended in cases of hamstring muscle damage. In the event edema and hemorrhage occur in the injured area, these two imaging methods make it possible to make a diagnosis [24]. Magnetic resonance imaging is considered preferable when damage is found inside the muscle tissue, or for example, when mild local edema exists or when an old scar is present as a result of a previous injury $[12,13,25]$.

\section{Treatment}

Immediately after injury occurs, it is recommended to put a cold compress on the sensitive area. Cryotherapy is proposed to reduce the inflammatory response to injured tissue as well as decrease edema, hematoma formation, and pain [26]. Raising the injured leg will help reduce hydrostatic pressure and limit pooling of interstitial fluid in the area where the tear occurred. If a hematoma is formed, it may be drained. In order to proceed to the next stage, the soccer player should be able to walk around without pain and in addition, to perform isometric contraction of the hamstring with sub-maximal [50-70\%] force when he is lying in a prone position and the knee is flexed at 90 degrees [11-13]. Non-steroidal anti-anti-inflammatory drugs are an almost universally accepted treatment, but it would be beneficial to delay the treatment until 2-4 days after the injury, because they interfere with cell chemotaxis, necessary for the repair and remodeling of regenerating muscle [27].

At a later stage, the involved limb may be fixated for only 3-7 days. Extended fixation may cause excess scarring in the area of the tear. Moderate mobilization up to the pain threshold will prevent adhesions within soft tissues and will improve blood flow to the damaged area. Afterwards, the injured muscle may 
be gradually mobilized by isometric contraction, but without resistance of the care giver up to the pain threshold. Active mobilization of the muscle will start only if isometric contraction does not cause pain. In the beginning, this action will be performed without resistance and will be gradually mobilized according to how the patient feels. If the soccer player experiences pain, the intensity should be decreased [4]. At the same time, the injured area may be heated in order to relax the muscle and improve blood flow to the region. In case the soccer player is prohibited from bearing weight on his injured leg for a long period of time, there is always a possibility of deep vein thrombosis developing and the use of anticoagulants should be considered. In order to proceed to the next stage, the soccer player must reach normal range of motion in the hip and knee joints, attain full muscle force in the hamstring and be able to run at least at $50 \%$ of his maximal speed without the emergence of pain [11-13].

The third stage after injury will include massage of the affected area, stretching the involved muscle and using hot packs and therapeutic ultrasound, although Dadebo et al. [9], investigated the relation between current flexibility training protocols, including stretching and hamstring strain rates in English professional football clubs. They found that stretching may be beneficial only if the technique employed and the stretch holding times are adequate. Isokinetic or concentric contraction of the muscle will only be possible when full range of motion in the hip and adjacent knee joint is reached. Eccentric mobilization of the muscle will only be permitted when a scar is formed at the site of the tear and is supposed to be performed gradually, against increasing resistance [11-13]. Concentric exercise is begun before eccentric exercise because eccentric contraction causes greater force than concentric contraction [28]. Running and later on, sprint training may begin as long as they do not cause pain in the posterior compartment of the thigh [4,11-13].

\section{Criteria for return to sport activities}

In order to enable a soccer player to return to the field, he must reach full range of motion in the joints of the injured hip and knee. Evaluation will be performed while the player is lying in a supine position, the thigh flexed at 90 degrees and the examining physician extends the knee joint to maximal range. The absence of pain in the posterior compartment of the involved thigh permits the soccer player to return to sports activity [29]. Before return to competitive activity, force as well as flexibility of the injured hamstring should be almost completely identical to those of the opposite leg [11-13]. According Heiderscheit et al. [12] and Sherry et al. [30] rehabilitation protocol, the athlete will be ready to return to play once he has met the following criteria: full range of motion, full-speed sprinting, and soccer specific-movements symptoms free.

Surgery is rarely considered for the treatment of muscle strain. With complete rupture of the proximal or distal attachment of the musculo-tendinous complex into bone, surgery is a realistic consideration [4].

There is no doubt that the soccer player must adhere to suitable preparation for physical activity. This will include active warm-up, exercise for flexibility and stretching of muscles and tendons, learning specific motor skills required for soccer, maintaining a balance between the force of the hamstrings and the quadriceps and perform exercises to stabilize the trunk with eccentric work. All of these may prevent recurrent injury of the hamstring muscles and enable the soccer player to continue with competitive activity $[6,13]$.

\section{References}

1. Ekstrand J, Gillquist J. Soccer injuries and their mechanisms: a prospective study. Med Sci Sports Exerc. 1983; 15(3):267-70.

2. Garrett WE Jr. Muscle strain injuries. Am J Sports Med. 1996; 24(6 Suppl):S2-8.

3. Feeley BT, Kennelly S, Barnes RP, Muller MS, Kelly BT, Rodeo SA, et al. Epidemiology of National Football League training camp injuries from 1998 to 2007. Am J Sports Med. 2008; 36(8):1597-603. doi: $10.1177 / 0363546508316021$.

4. Petersen J, Holmich P. Evidence based prevention of hamstring injuries in sport. Br J Sports Med. 2005; 39(6):319-23.

5. Askling C, Karlsson J, Thorstensson A. Hamstring injury occurrence in elite soccer players after preseason strength training with eccentric overload. Scand J Med Sci Sports. 2003; 13(4):244-50.

6. Sherry MA, Best TM, Silder A, Thelen DG, Heiderscheit CB. Hamstrings strains: Basic science and clinical research applications for preventing the recurrent injury. Strength Conditioning J. 2011; 33(3):56-71. doi: 10.1519/SSC.0b013e31821e2f71

7. Woods C, Hawkins RD, Maltby S, Hulse M, Thomas A, Hodson A, et al. The football association medical research programme: an audit of injuries in professional football-analysis of hamstring injuries. $\mathrm{Br} \mathrm{J}$ Sports Med. 2004; 38(1):36-41

8. Yu B, Queen RM, Abbey AN, Liu Y, Moorman CT, Garrett WE.) Hamstring muscle kinematics and activation during overground sprinting. J Biomech 2008. 41(15):3121-6.

9. Dadebo B, White J, George KP. A survey of flexibility training protocols and hamstring strains in professional football club in England. Br J Sports Med. 2004; 38(4):338-94.

10. Sole G, Milosavljevic S, Nicholson H, Sullivan SJ. Altered muscle activation following hamstring injuries. Br J Sports Med. 2012; 46(2):118-23. doi: 10.1136/bjsm.2010.079343.

11. Mendiguchia J, Brughelli M. A return-to-sport algorithm for acute hamstring injuries. Phys Ther Sport. 2011; 12(1):2-14. doi: 10.1016/j. ptsp.2010.07.003.

12. Heiderscheit BC, Sherry MA, Silder A, Chumanov ES, Thelen DG. Hamstring strain injuries: recommendations for diagnosis, rehabilitation, and injury prevention. J Orthop Sports Phys Ther. 40(2):67-81. doi: 10.2519/jospt.2010.3047.

13. Edouard P, Serra JM, Pruvost J, et al. Les lésions musculaires des ischio-jambiers. J Traumatol Sport. 2013; 30:176-184.

14. Croisier JL. Factors associated with recurrent hamstring injuries. Sports Med. 2004; 34(10):681-95.

15. Engebretsen AH, Myklebust G, Holme I, Engebretsen L, Bahr R. Intrinsic risk factors for hamstring injuries among male soccer players: a prospective cohort study. Am J Sports Med. 2010; 38(6):1147-53. doi: 10.1177/0363546509358381.

16. Ekstrand J, Hagglund W, Walden M. Injury incidence and injury 
patterns in professional football: the UEFA injury study. Br J Sports Med. 2011; 45(7):553-8. doi: 10.1136/bjsm.2009.060582.

17. Brotzman SB, Manske RC. Clinical orthopedic rehabilitation: an evidence-based approach. Elsevier mosby. 2011; 416-28.

18. Opar DA, Williams MD, Shield AJ. Hamstring strain injuries: factors that lead to injury and re-injury. Sports Med. 2012; 42(3):209-26. doi: 10.2165/11594800-000000000-00000.

19. Askling CM, Tengvar M, Saartok T, Thorstensson A. Acute first-time hamstring strains during high-speed running: a longitudinal study including clinical and magnetic resonance imaging findings. Am J Sports Med. 2007; 35(2):197-206.

20. Thelen DG, Chumanov ES, Hoerth DM, Best TM, Swanson SC, Li L. Hamstring muscle kinematics during treadmill sprinting. Med Sci Sports Exerc. 2005; 37(1):108-14.

21. Lefevre N, Bohu Y, Klouche S, Naouri JF, Herman S. Return to sport after surgical repair of proximal hamstring ruptures: A systematic review. J Traumatol Sport. 2014; 31(1):28-36.

22. Lefevre N, Naoury J-F, Vincent D, et al Rupture haute des tendons ischiojambiers chez les sportifs. A propos d'une série de neuf cas opérés. J Traumatol Sport. 2007; 24:143-147.

23. Burnel M, Croisier JL, Zeevaert B, Crielaard JM. Proximal disinsertion and complete rupture of the semitendinous: case study and review of the literature. J Traumatol Sport. 2005; 22(3):158-65.
24. Connell DA, Schneider-Kolsky ME, Hoving JL, Malara F, Buchbinder R, Koulouris G, et al. Longitudinal study comparing sonographic and MRI assessments of acute and healing hamstring injuries. Am J Roentgenol 2004; 183(4):975-84.

25. Koulouris G, Connell D. Hamstring muscle complex: an imaging review. Radiographics. 2005; 25(3):571-86.

26. Swenson C, Sward L, Karlssson J. Cryotherapy in sports medicine. Scand J Med Sci Sports. 1996; 6(4):193-200.

27. Clanton TO, Coupe KJ. Hamstring strains in athletes: diagnosis and treatment. J Am Acad Orthop Surg. 1998; 6(4):237-48.

28. Verral GM, Slavotinek JP, Barnes PG, Fon GT, Spriggins AJ. Clinical risk factors for hamstring muscle strain injury: a prospective study with correlation of injury by magnetic resonance imaging. Br J Sports Med. 2001; 35(6):435-9.

29. De Vos RJ, Reurink G, Goudswaard GJ, Moen MH, Weir A, Tol JL. Clinical findings just after return to play predict hamstring re-injury, but baseline MRI findings do not. Br J Sports Med. 2014; 48(18):1377-84. doi: 10.1136/bjsports-2014-093737.

30. Sherry MA, Best TM. A comparison of 2 rehabilitation programs in the treatment of acute hamstring strains. J Orthop Sports Phys Ther. 2004; 34(3):116-25. 